\title{
Quantifying key sources of variability in cover crop reduction of $\mathbf{N}$ leaching
}

\author{
E. I. Teixeira, P. Johnstone, E. Chakwizira, J. de Ruiter, B. Malcolm, N. Shaw, R. Zyskowski, \\ E. Khaembah, J. Sharp, E. Meenken, P. Fraser, S. Thomas, H. Brown and D. Curtin \\ The New Zealand Institute for Plant \& Food Research Limited, Private Bag 4704, Christchurch, New \\ Zealand \\ Email: edmar.teixeira@plantandfood.co.nz
}

\begin{abstract}
The effectiveness of cover crops in mitigating nitrogen $(\mathrm{N})$ leaching is highly variable. The reasons for this variability are unclear and difficult to isolate from field experimentation only. A modelling experiment to represent a cover crop (forage-wheat) and spring crop (silage-maize) sequence, using 30 years of historical weather data input from Lincoln, Canterbury (New Zealand), was set up to quantify key sources of this variability in cover crop effectiveness. A locally calibrated biophysical model (APSIM) was used to simulate the effects of crop management (four sowing dates for cover crops from mid-March to mid-June) and two soil water holding capacity (WHC) rates on the effectiveness of $\mathrm{N}$ leaching mitigation. Crop management determined the average effectiveness of cover crops, with consistently lower effectiveness at later sowing dates. The soil WHC effect was less prominent on cover crop effectiveness. Within any sowing date by soil WHC combination, the variability in cover crop effectiveness was mostly driven by the stochastic effects of weather on plant growth and soil $\mathrm{N}$ processes. These results can inform impact assessments about the contribution of management and environmental factors that control the effectiveness of cover crops to mitigate $\mathrm{N}$ leaching.
\end{abstract}

Keywords: $\quad$ APSIM, cover crops, nitrogen leaching, water quality 


\section{INTRODUCTION}

Nitrogen leaching to groundwater is an important environmental concern, particularly in regions of intensive agriculture, such as the Canterbury plains of New Zealand. The use of winter cover crops is a well established management practice to recover excess soil $\mathrm{N}$ and reduce risks of $\mathrm{N}$ leaching (Cameron et al., 2013; Constantin et al., 2010). However, the effectiveness of cover crops in reducing $\mathrm{N}$ leaching has been shown to be widely variable (Restovich et al., 2012; Whitmore and Schroder, 2007). Current literature suggests that possible factors influencing this variability include crop management, soil type and seasonal weather conditions (Francis et al., 1998; Fraser et al., 2013). It is not easy to quantify the extent of contribution of each of these different factors solely based on the analyses of data from individual field experiments, because of the multiple combinations of management, soil types and weather conditions. Therefore, we used a biophysical model to isolate the effect of these sources of variability by setting up a simulation experiment in response to historical weather data, for a site in the Canterbury plains of New Zealand, considering two soil types and management represented by contrasting sowing dates of cover crops.

\section{MATERIALS AND METHODS}

The modelling case study was designed for Lincoln, Canterbury, New Zealand $\left(43^{\circ} 37^{\prime} \mathrm{S}, 1^{172^{\circ}} 28^{\prime} \mathrm{E}\right)$. The Agricultural Production Systems sIMulator (APSIM 7.7) (Holzworth et al., 2014) was used to simulate the effect of four contrasting sowing dates of cover crops (15 March, 15 April, 15 May and 15 June) in response to 30 years of historical weather data (Figure 1). The cover crop was followed by a spring silage maize crop sown on 15 October. The date of harvest was fixed as 15 September for the cover crop and 10 March for the silage maize. Two soils with contrasting water holding capacity (WHC) of 144 and $288 \mathrm{~mm}$ (within a 0-1.8 m depth) were considered as additional factors in the simulation. The control treatment was simulated as a fallow condition (i.e. bare soil) in which only maize crops were simulated in spring, without the presence of cover crops in winter. To isolate inter-annual weather variability effects, the soil conditions were reinitialized annually, assuming a high mineral $\mathrm{N}$ load of $160 \mathrm{~kg} \mathrm{~N} / \mathrm{ha}$ and soil water at field capacity in early autumn.
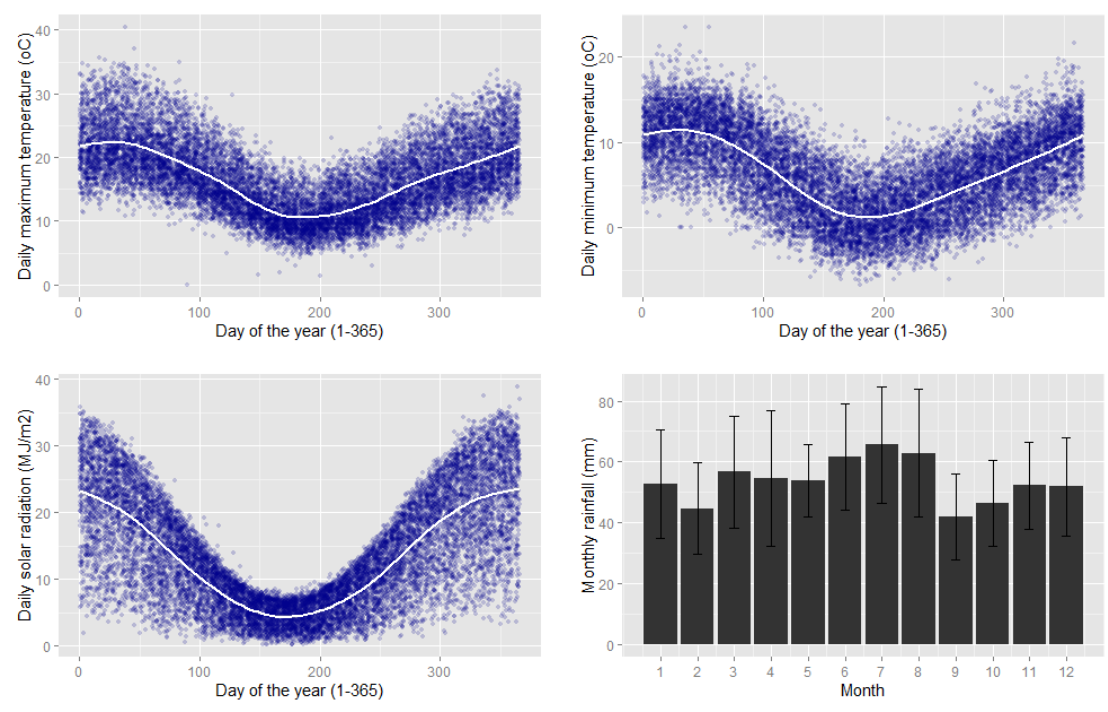

Figure 1. Weather from Lincoln, Canterbury, New Zealand (1970 to 2000). Lines indicate long-term averages; points are individual daily values from 1-Jan (DOY 1) to 31-Dec (DOY 365). Error bars are one standard deviation for the 30-year period. 
The model was calibrated with local data (Figure 2) from a winter-wheat and silage maize crop rotation at Lincoln, Canterbury (de Ruiter et al., 2009).
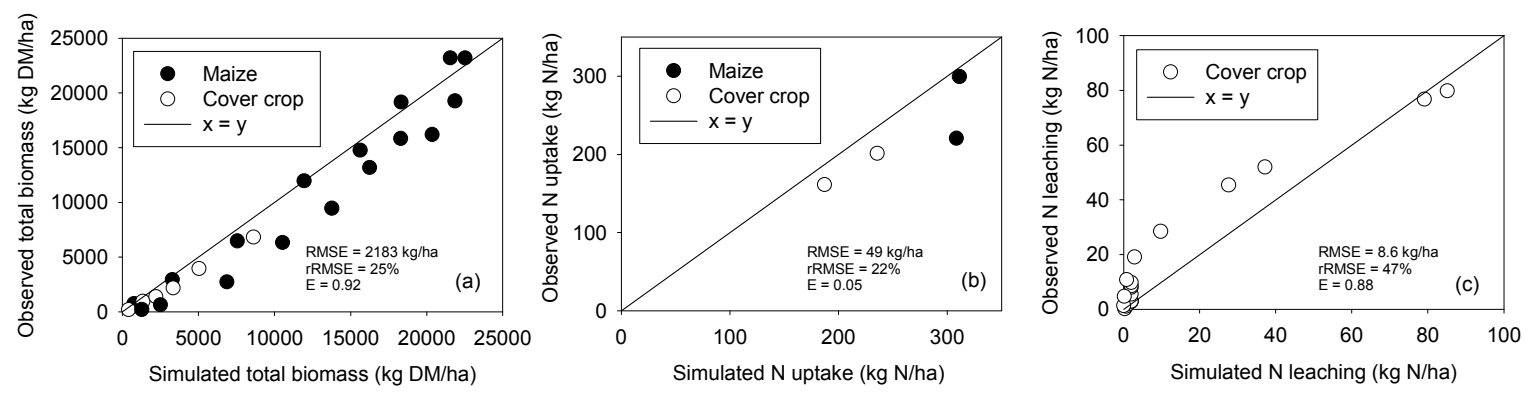

Figure 2. Simulated and observed values of total biomass (a), nitrogen (N) uptake (b) and N leaching (c) for silage maize crops and forage winter cover crops for the calibration dataset, at Lincoln, Canterbury, New Zealand.

The effectiveness of cover crops was calculated both as the relative (\%) difference between $\mathrm{N}$ leaching loss at $90 \mathrm{~cm}$ depth for each "sowing date by soil WHC by year" combination in relation to the simulated fallow condition (no cover crop) for the same "soil WHC by year" combination.

\section{RESULTS}

Model simulations showed a wide range of median biomass dry matter yield $(\sim 1.7$ to $7 \mathrm{Mg} / \mathrm{ha})$ and nitrogen uptake ( $\sim 50$ to $200 \mathrm{~kg} \mathrm{~N} / \mathrm{ha}$ ) of cover crops (Figure 3). Silage maize yield estimates were unaffected by cover crop treatments with an average of $19 \mathrm{Mg} / \mathrm{ha}$. However, there was a large variability in cover crop biomass yield and $\mathrm{N}$ uptake within each sowing date by soil scenario combinations. For example, for the earliest sowing date in the low WHC soil, biomass ranged from $\sim 5$ to $7.5 \mathrm{Mg} / \mathrm{ha}$ and $\mathrm{N}$ uptake from $\sim 125$ to $200 \mathrm{~kg} / \mathrm{ha}$ in response to inter-annual weather variability.

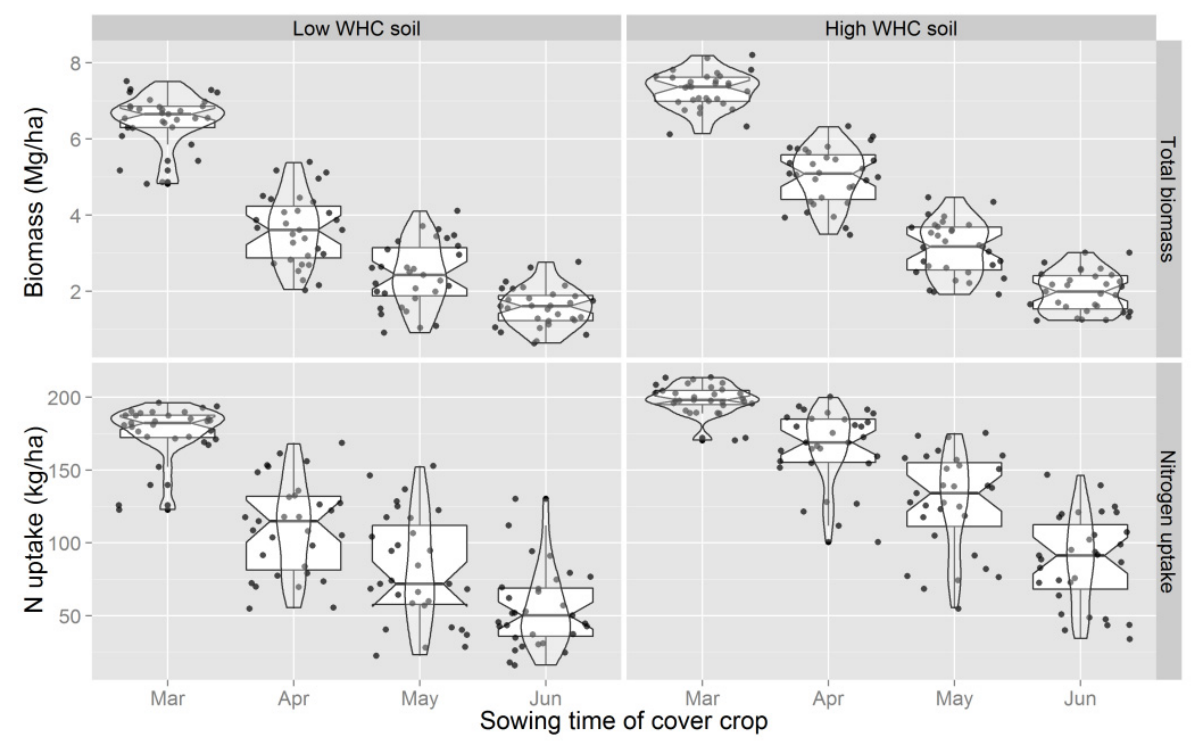

Figure 3. Simulated total biomass dry matter yield and nitrogen $(\mathrm{N})$ uptake of cover crops sown at different times into two soils with contrasting water holding capacities (WHC) (144 and $288 \mathrm{~mm}$ for a 1.8-m depth profile) based on 30 years of historical weather at Lincoln, Canterbury, New Zealand. Box plots show median, the $25^{\text {th }}, 75^{\text {th }}$ percentile and points represent individual years. 
Late sowing dates consistently reduced the effectiveness of cover crops in mitigating $\mathrm{N}$ leaching (Figure 4). Median values ranged from $>80 \%$ for the March sowing date to $<15 \%$ for the June sowing date. The effectiveness of cover crops was also variable within each individual "sowing date by soil WHC" scenario. For example, reduction in leaching ranged from $\sim 60$ to $100 \%$ in the March sowing date and 25 to $80 \%$ for the April sowing date, with lower minimum values for the low WHC soil. Soil WHC showed a relatively lower impact on the effectiveness of cover crops in mitigating $\mathrm{N}$ leaching than those of sowing dates and inter-annual weather variability.

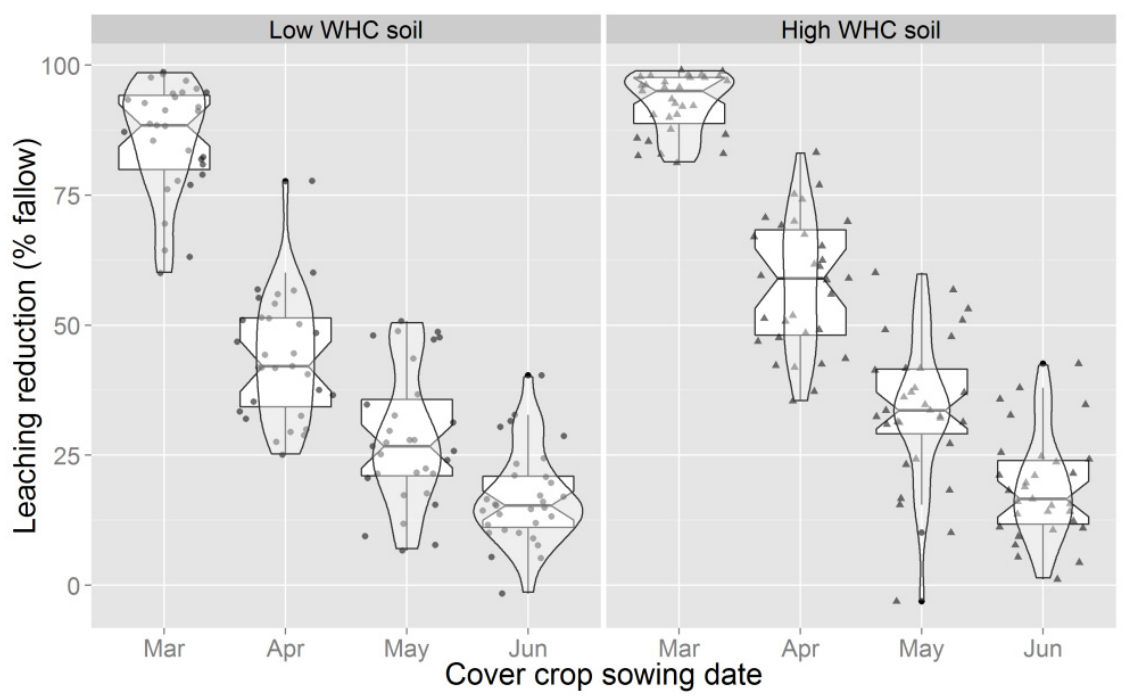

Figure 4. Simulated effectiveness of cover crops as relative (\%) reduction in nitrogen leaching (in relation to fallow) due to cover crops sown at different times into two soils with contrasting water holding capacity capacities (WHC) of 144 and $288 \mathrm{~mm}$. Points represent individual years at Lincoln, Canterbury, New Zealand (1970-2000).

\section{DISCUSSION AND CONCLUSIONS}

The modelling experiment further confirms the value of winter cover crops in mitigating $\mathrm{N}$ leaching as illustrated in recent meta-analysis studies (Quemada et al., 2013; Tonitto et al., 2006). The model simulations captured the direction of response of both biomass and $\mathrm{N}$ dynamics over a wide range of values (Figure 2). The slight overestimation of crop biomass partially explained the higher $\mathrm{N}$ uptake and $\mathrm{N}$ leaching underestimation. The relatively higher rRMSD for $\mathrm{N}$ leaching is in agreement with recent studies that highlight uncertainty on estimates of absolute $\mathrm{N}$ losses because of the limited quantitative understanding of soil processes controlling $\mathrm{N}$ losses, and the challenges in representing spatial variability of $\mathrm{N}$ leaching in the field (van der Laan et al., 2013). To minimize these effects, our analysis relied on the relative comparison of values from cover crop and fallow simulations. Simulated effectiveness of winter cover crops in mitigating N leaching was largely driven by the stochastic effect of inter-annual weather variability. This caused widely variable results within any given climate by soil by management combination. This variability was possibly driven by the concomitant responses of plant (e.g. light interception and photosynthesis) and soil (e.g. drainage and $\mathrm{N}$ mineralization) processes to environmental factors (solar radiation, temperature and rainfall) across and within years, that largely influence the timing and magnitude of $\mathrm{N}$ uptake and leaching rates (Vos and van der Putten, 1997). Crop management was a major determinant of the average effectiveness of cover crops, in contrast with the limited effect of the soil WHC range considered in this study. There was a consistent decline in the effectiveness of $\mathrm{N}$ leaching mitigation with delayed sowing dates. These findings highlight the importance of considering different sources of variability in impact assessments of $\mathrm{N}$ leaching, and they provide an example of the heuristic value of biophysical models for complementing knowledge from experimental findings.

\section{ACKNOWLEDGMENTS}

Research was completed as part of the Forages for Reduced Nitrate Leaching programme with principal funding from the New Zealand Ministry of Business, Innovation and Employment. The programme is a partnership between DairyNZ, AgResearch, Plant \& Food Research, Lincoln University, Foundation for Arable 
Teixeira et al., Quantifying key sources of variability in cover crop reduction of $\mathrm{N}$ leaching

Research (FAR) and Landcare Research. We thank Megan Gee, PFR, for invaluable support with the bibliography.

\section{REFERENCES}

Cameron, K. C., Di, H. J., and Moir, J. L. (2013). Nitrogen losses from the soil/plant system: A review. Annals of Applied Biology, 162 (2): 145-173.

Constantin, J., Mary, B., Laurent, F., Aubrion, G., Fontaine, A., Kerveillant, P., and Beaudoin, N. (2010). Effects of catch crops: No till and reduced nitrogen fertilization on nitrogen leaching and balance in three long-term experiments. Agriculture Ecosystems \& Environment, 135 (4): 268-278.

de Ruiter, J., Fletcher, A., Maley, S., and Sim, R. (2009). Aiming for 45 t/ha per annum: Yield of supplementary feed crops grown in sequences designed for maximum productivity. Proceedings of the New Zealand Grassland Association 71: 107-116.

Francis, G. S., Bartley, K. M., and Tabley, F. J. (1998). The effect of winter cover crop management on nitrate leaching losses and crop growth. Journal of Agricultural Science, 131 (3): 299-308.

Fraser, P. M., Curtin, D., Harrison-Kirk, T., Meenken, E. D., Beare, M. H., Tabley, F. J., Gillespie, R. N., and Francis, G. S. (2013). Winter nitrate leaching under different tillage and winter cover crop management practices. Soil Science Society of America Journal, 77 (4): 1391-1401.

Holzworth, D. P., Huth, N. I., deVoil, P. G., Zurcher, E. J., Herrmann, N. I., McLean, G., Chenu, K., van Oosterom, E. J., Snow, V., Murphy, C., Moore, A. D., Brown, H., Whish, J. P. M., Verrall, S., Fainges, J., Bell, L. W., Peake, A. S., Poulton, P. L., Hochman, Z., Thorburn, P. J., Gaydon, D. S., Dalgliesh, N. P., Rodriguez, D., Cox, H., Chapman, S., Doherty, A., Teixeira, E. I., Sharp, J., Cichota, R., Vogeler, I., Li, F. Y., Wang, E., Hammer, G. L., Robertson, M. J., Dimes, J. P., Whitbread, A. M., Hunt, J., van Rees, H., McClelland, T., Carberry, P. S., Hargreaves, J. N. G., MacLeod, N., McDonald, C., Harsdorf, J., Wedgwood, S., and Keating, B. A. (2014). APSIM - Evolution towards a new generation of agricultural systems simulation. Environmental Modelling \& Software, 62: 327-350.

Quemada, M., Baranski, M., Nobel-de Lange, M. N. J., Vallejo, A., and Cooper, J. M. (2013). Meta-analysis of strategies to control nitrate leaching in irrigated agricultural systems and their effects on crop yield. Agriculture Ecosystems \& Environment, 174: 1-10.

Restovich, S. B., Andriulo, A. E., and Portela, S. I. (2012). Introduction of cover crops in a maize-soybean rotation of the Humid Pampas: Effect on nitrogen and water dynamics. Field Crops Research, 128 (14): $62-70$.

Tonitto, C., David, M. B., and Drinkwater, L. E. (2006). Replacing bare fallows with cover crops in fertilizerintensive cropping systems: A meta-analysis of crop yield and $\mathrm{N}$ dynamics. Agriculture, Ecosystems \& Environment, 112 (1): 58-72.

van der Laan, M., Annandale, J. G., Bristow, K. L., Stirzaker, R. J., du Preez, C. C., and Thorburn, P. J. (2013). Modelling nitrogen leaching: Are we getting the right answer for the right reason? Agricultural Water Management, 133: 74-80.

Vos, J., and van der Putten, P. E. L. (1997). Field observations on nitrogen catch crops. I. Potential and actual growth and nitrogen accumulation in relation to sowing date and crop species. Plant and Soil, 195 (2): 299-309.

Whitmore, A. P., and Schroder, J. J. (2007). Intercropping reduces nitrate leaching from under field crops without loss of yield: A modelling study. European Journal of Agronomy, 27 (1): 81-88. 